\title{
A change at the tiller
}

\section{Robin Spiller}

$\mathrm{P}$ rofessor Michael Farthing stepped down from the editorship of Gut in mid December 2002 after a distinguished editorship, which lasted seven years. During that time Gut steadily increased its impact and its international appeal. Our thanks go to Mike for this very substantial contribution and it will be our endeavour to build on his success. Simultaneously Professor Nick Wright, Professor Tom MacDonald, and Dr Ian Forgacs stood down as associate editors, posts which they had held for more than four years. Our special thanks to them for their long and distinguished service. They will now join the Editorial Board where we will be able to continue to draw on their expertise and enthusiasm.

This is an exciting time to take over as editor of such a journal, since electronic publication is opening up new vistas of potential means of spreading knowledge. While a paper-based journal is certainly likely to continue in existence for the foreseeable future, the website offers fantastic opportunities, both for speeding up the process of manuscript processing and publishing and also as a means of disseminating information and binding the academic community together without regard to geographical boundaries.

The journal has many constituencies the most important of which are the readership and the authors. Each have their own needs and a successful journal must seek to balance these satisfactorily. A fair and speedy review process is the top priority for authors, with rapid publication of important new findings close behind. The priorities for readers are slightly different with readability, interest, and explanation of how new information fits with existing knowledge and practice being all important.

We are responding to these needs in a number of ways. Rapid and efficient processing of manuscripts has been substantially improved by the introduction of electronic publishing. Our average time to decision is now 25 days from first submission. However, for some papers there are unacceptable delays related either to difficulty in finding reviewers or in contradictory reviews which require adjudication. In order to address this issue, we intend to expand our editorial board, both numerically and with regard to country of origin. Three of the previous associate editors are continuing in post, Professor Jan Tack from Leuven in Belgium, Professor David Adams from Birmingham, UK, and Professor John Atherton from Nottingham, UK, providing much needed continuity and invaluable advice during the handover period. New appointments include Professor Ray Playford from The Royal PostGraduate Medical School, London and Professor Alistair Watson from Royal Liverpool University Hospital, together with Professor Jurgen Scholmerich from Regensburg, Germany. We have also appointed Anna Mae Diehl from Johns Hopkins University, USA. This has the advantage of internationalising the journal and providing access to a wider range of viewpoints and reviewers. In the past there has been an undue delay between acceptance of a manuscript and publication and it is our target to reduce this to an average of four months. Using electronic publishing, we can in fact fast track some exciting articles and have them published on the web within a much shorter time. This has obvious advantages for authors since immediacy of publication is all important, both in spreading knowledge but also in fuelling further research via successful grant applications.

The needs of our readership are being addressed in very different ways. We are introducing a new feature entitled "Recent Advances in Clinical Practice" which will cover significant scientific advances that impact directly on clinicians. The aim here is to have an area in the journal which, practicing clinicians-far from the bench top or laboratory-will find relevant to their needs. We are also replacing science and clinical alerts with a new feature called "JournalScan". This will provide a service to those who don't have time to read many other journals. Items, which will be identified, will be those which are worth a further read and which are likely to impact on clinical practice. We have gathered together a team with expertise covering a broad range of interests. The page will be edited by Professor Richard Logan, who will co-ordinate contributions from Dr Guru Aithal, Mr Richard Charnley, Dr Simon Travis, and Dr Ian Penman.

As more of our membership acquire the internet habit, we are planning to make extensive use of data supplements, whereby authors can provide extra figures and tables, and longer versions of their papers online. We also plan to use the power of the web to provide medical education through a new feature entitled "Gut Tutorials". We are currently in negotiations to appoint an editor and will be approaching senior supporters of Gut to write didactic interactive educational material, which will be case based but will use all the power of the web to link both to key articles and also to videos and images that available on the web. The BMJ Publishing Group have a substantial IT capability and I would encourage you to watch this spot for future developments. We certainly wish to encourage electronic communication and discussion of articles, which we have published since the discussion is often of great interest and takes the field forward.

In addition, we are collaborating with the National Library of Medicine for all but the last three years' editions of Gut to be available electronically free of charge to ensure that articles published in Gut receive the widest possible exposure within the scientific community. All generations believe they live in "stirring times". I certainly feel that we are on the brink of an extraordinary explosion in knowledge dissemination. Institutions not adapting to these changing times will atrophy and decay. It is in the endeavour of myself and my team of associate editors to ensure that this does not happen to Gut.

\section{R Spiller} Editor

Correspondence to: Professor R Spiller, University of Nottingham, Division of Gastroenterology, School of Medical \& Surgical Sciences, C Floor, South Block, University Hospital, Nottingham NG7 2UH Robin.Spiller@nottingham.ac.uk 